\title{
COMPARATIVE EFFECTIVENESS OF DISINFECTANTS WITH PHENOL ON MULTIDRUG RESISTANT BACTERIA AND FUNGI ISOLATED FROM THE CLINICAL SAMPLE - AN IN VITRO PRELIMINARY STUDY
}

\author{
Mannur Sharada, Jayaram Ashok, Hiremath Savitha, .H.Mahesh, E.R. Nagaraj
}

1. Associate Professor,. Department of Microbiology, Sri Siddhartha Medical College, Tumkur.

2. Professor. Department of Community Medicine, Sri Siddhartha Medical College, Tumkur.

3. Post Graduate Student, Department of Microbiology, Sri Siddhartha Medical College, Tumkur.

4. Assistant Professor. Department of Community Medicine, Sri Siddhartha Medical College, Tumkur.

5. Professor \& HOD, Department of Microbiology, Sri Siddhartha Medical College, Tumkur.

\section{CORRESPONDING AUTHOR:}

Dr. Sharadadevi Mannur. Y,

Associate Professor,

Department of Microbiology,

Sri Siddhartha Medical College, Tumkur.

E-mail-drysdm71@yahoo.co.in

ABSTRACT: BACKGROUND: The emergence of multidrug resistant (MDR) microorganism infections has generated considerable attention in the recent past. The primary goal of infection control procedures is to prevent cross contamination between patients as well as between patients and health care providers. This can be achieved by the safe disposal of body fluids and cultures having such microorganisms from the hospital ward and laboratory.

This study aimed at comparing the efficacy of commercially available disinfectants on microorganisms isolated from clinical samples. MATERIAL AND METHOD: Four commonly used disinfectants namely Savlon, 70\% Ethanol, Dettol and Lysol were tested for their Antibacterial and Anti fungal effects against multidrug resistant bacteria and fungi isolated from clinical samples from inpatients admitted to Sri Siddhartha Medical College Hospital, Tumkur. Multi- drug resistant (MDR) microorganisms E. coli, S. aureus, K. pneumoniae, P. aeruginosa, C. albicans, A. niger and A flavus isolated from clinical samples were used for testing the effectiveness of disinfectants. Agar Welldiffusion method using Mueller Hinton Agar and Modified Muller Hinton agar was used to assess the effectiveness of disinfectants. Phenol was considered to be the standard disinfectant to which other disinfectants were compared. The zone of inhibition (ZOI) for each isolate was measured. These were compared to the ZOI of Phenol $(40 \mathrm{~mm})$. The results were statistically analyzed by descriptive statistical methods. RESULTS: The ZOI against S. aureus and E. coli of Savlon was $33 \mathrm{~mm} \& 34 \mathrm{~mm}$ and for Dettol 38mm \& $37 \mathrm{~mm}$, respectively. But for K. pneumoniae the ZOI was $29 \mathrm{~mm} \& 30 \mathrm{~mm}$ and for P. aeruginosa was $24 \mathrm{~mm}$ and $30 \mathrm{~mm}$ for Savlon and Dettol, respectively. The ZOI for $70 \%$ ethanol ranged from $32 \mathrm{~mm}$ to $34 \mathrm{~mm}$ on all the isolates. The ZOI for Lysol ranged from $22 \mathrm{~mm}$ to $24 \mathrm{~mm}$ on isolates. CONCLUSION: The disinfectants -- Savlon and Dettol can be used as alternatives to phenol and sodium hypochloride solution to manage liquid spills in small health care settings. And agar well diffusion method can be used to assess the effectiveness of disinfectants, used in the hospitals to have quality control on the disinfectants.

KEY WORDS: Disinfectants, Multidrug resistant organisms, Agar well diffusion method 


\section{ORIGINAL ARTICLE}

INTRODUCTION: The emergence of Multi Drug Resistant (MDR) microorganism infections has generated considerable attention in the recent past. Despite remarkable progress in our knowledge of risk factors, prevention and control measures, the incidence of nosocomial infections has not decreased, and many outbreaks have been caused by new multidrug-resistant pathogens.

Reduction in morbidity and mortality from these can be achieved by proper infection control procedures, which can prevent cross contamination between patients as well as between patients and health care providers $(1,2)$. This can be achieved by proper use of disinfectants and scientific disposal of biomedical wastes from laboratories and hospitals. The effect of various disinfectants on MDR isolates varies with type of disinfectant, dilutions used and the time of exposure to it as well as type of bacterial isolates. The resistance of pathogens to disinfectant is an emerging problem and is due to presence of integrons, super integrons and efflux mechanisms in the pathogens $(4,5,6)$. In literature review, not many studies have done to test the efficacies of disinfectants by agar well diffusion method.

Hence the purpose of this study was, to evaluate the bactericidal and fungicidal efficacies of four commercially available disinfectant solutions, which are commonly used in wound cleansing, in clinics and house hold purpose, on different MDR isolates and fungi isolated from hospitalized patients.

MATERIAL AND METHODS: This study was conducted at Sri Siddhartha Medical College, Tumkur, Karnataka, India, during the period from September to October 2012, Department of Microbiology.

BACTERIAL ISOLATES: The microorganisms were isolated from clinical samples of patients admitted in the wards. The isolates were identified by using standard protocols followed in the Department of Microbiology. These isolates were resistant to $\geq 1$ agent in $\geq 3$ antimicrobial categories one or more classes of antibiotics

DISINFECTANTS USED IN THE STUDY: The undiluted concentrations of disinfectants used for the study were - Savlon, Dettol, Lysol and 70\% ethanol.

AGAR WELL DIFFUSION METHOD: The efficacy of four disinfectants were first tested on the ATCC (American Type Culture Collection) strains of Escherichia coli 25922, Staphylococcus aureus 25923, Klebsiella pneumoniae 700603 and Pseudomonas aeruginosa 27853. Later test organisms were tested on same disinfectants. The turbidity of bacterial suspension was matched to the $0.5 \mathrm{Mc}$ Farland tube. Lawn culture on Muller Hinton Agar was made and $6 \mathrm{~mm}$ bore was dug with the help of cork borer. 100 microlitre of disinfectants was dispensed in the dug well. After 24 hours the zone of inhibition (ZOI) was measured using ZOI measuring scale. Same methodology was done for Candida albicans, Aspergillus niger and Aspergillus flavus, using Modified Mueller Hinton agar.

C. albicans (ATCC 90028) and A. flavus (ATCC 204304) are used as control strains for fungal isolate in the study

5\%Phenol was taken as standard disinfectant to which other disinfectants are compared and normal saline was used as negative control. Test was done in triplicates to get mean value of ZOI (10 16). 


\section{ORIGINAL ARTICLE}

Statistical Analysis: Statistical analysis was performed after collecting the zone of inhibition measurements. Data collected was entered in Microsoft excel 2007 and analyzed using descriptive statistics.

RESULTS: The susceptibility testing of the four commonly used disinfectant formulations against the test clinical isolates showed that most of the test clinical isolates had good susceptibility to some of the disinfectant formulations. The Savlon was $80.95 \%$ and $82.5 \%$ effective on Escherichia coli and Staphylococcus aureus in comparison with 5\% Phenol. The Dettol was $90.4 \%$ and $92.5 \%$ effective against Escherichia coli and Staphylococcus aureus in comparison with 5\% Phenol. 70\% Ethanol was 80.95\%, 80\%, 87.80\% and 91.66\% effective on Escherichia coli, Staphylococcus aureus, Klebsiella pneumoniae and Pseudomonas aeruginosa. Lysol was least effective with $66.66 \%, 67.5 \%, 56.00 \%$ and $55.55 \%$ on MDR pathogens. All four disinfectants used in the study were $100 \%$ effective on Candida albicans, Aspergillus niger and Aspergillus flavus. Savlon was more than $80 \%$ effective against Escherichia coli and Staphylococcus aureus isolates in comparison to Phenol. 70\% Ethanol was effective against all tested MDR isolates with efficacy being more than $80 \%$ as compared to Phenol. Dettol was $90 \%$ effective against Escherichia coli, Staphylococcus aureus and Pseudomonas aeruginosa in comparison to Phenol.

DISCUSSION: The application of the principles of disinfection and sterilization to effective infectious waste (IW) management must be viewed carefully. The methods for achieving suitable disinfection and sterilization for the on-site treatment of infectious wastes are very limited. The on-site treatment has 3 potential advantages, (1) assurance that wastes are properly treated, (2) minimization of potential risk to personnel as material moves through the waste stream, and (3) cost-effectiveness.

Chemical disinfection is appropriate for the inactivation of liquid wastes, such as cultures of etiologic agents, associated biologicals, and human blood and blood products. It can also serve to decontaminate fomites like metal cot, examination table and other metal articles coming in contact with patient in a small clinic or office, laboratory where contaminated swabs, disposable culture loops, etc., are placed in jars of disinfectant when steam sterilization or incineration are not available(1). Following increased circulation of pathogens that are non-susceptible to several disinfectants; numerous in-vitro tests have been developed to assess the effectiveness of various disinfectants in specific clinical situations (3).

Some of these disinfectants have certain limitations. The disinfectants like Sodium hypochlorite and phenol has pitting property on metal surfaces and steel equipments, damage painted surfaces and cause holes in the clothing.

Alabi OS (2012) studied the effectiveness of disinfectants - Dettol, Izal and Jik against multidrug resistant P. aeruginosa, S. aureus, Klebsiella species and Proteus species. The agar well diffusion method was adapted to assess the efficacies of the disinfectants. The study concluded that jik $(2.5 \%$ \& 5\% Sodium hypochlorite) disinfectant was effective in the dilutions prescribed by the manufacturer (2).

Charles A(2011) used agar well diffusion method to test the efficacy of extract of Alseodaphne semecarpifolia nees on anaerobic bacteria, aerobic bacteria like E. coli, S. aureus, Ps. mutans, P. mirabilis, S. enterititidis, K. pneumoniae, Enterobacter species, B. subtilis, fungi like A. niger, A. flavus, A. nidulans, Penicillium species and Mucor species(6,16). 
Nogbulie NJ et al (2008) compared the efficacies of disinfectants like Lysol, Dettol, Purit, Roberts and Wexcide in 1:100 dilutions against Streptococcus specie, Staphylococcus species, E. coli, Pseudomonas species and Bacillus species. They reported that the Pseudomonas species was susceptible to Lysol. Streptococcus species, E.coli and Proteus species was $80 \%$ susceptible to all the disinfectants used. Bacillus species was only $20 \%$ susceptible to all the disinfectants. Hence we concluded that selection of a disinfectant or antiseptics should be based on circumstances and should be active against gram positive as well as gram negative bacteria.

The undiluted concentration of Dettol and Savlon does not have any side effects. Hence can be used to disinfect wounds, culture plates and any spills containing the MDR bacteria.

In our study, Dettol was 90\% effective against Escherichia coli, Staphylococcus aureus and Pseudomonas aeruginosa and Savlon was $80.95 \%$ and $82.5 \%$ effective on Escherichia coli and Staphylococcus aureus in comparison with 5\% Phenol.

In conclusion, our study shows, the undiluted concentration of Savlon and Dettol can be used in the small laboratories, clinics and other health care providing centers for management of infectious liquid spills, infectious samples of patients and cultures from laboratories having MDR bacteria. The Agar well diffusion method can be used to have quality control on the regularly used disinfectants in the hospitals and laboratories, as the standard methods of tests for disinfectants are time consuming and laborious process. . The Agar well diffusion method is cheap and easy to do in any laboratory. Also many dilutions of disinfectant in question can be done in single agar plate.

LIMITATION OF THE STUDY: 1.We did not compare the four disinfectants with 5\% Sodium hypochlorite solutions. 2 . There is no standard reference method for this well diffusion method

RECOMMENDATION: 1 .More studies have to be conducted on other microorganisms. 2. Agar well diffusion method has to be standardized at the site where the test is being conducted.

ACKNOWLEDGEMENT: I would also like to thank the management and professor and head of the department of microbiology of our institution for their support to carry out this study. Then my sincere thanks to Mr. Anil Pasha and Mr. Purushotham, Technologists for their help in the laboratory of our institution

\section{REFERENCES}

1. Hugo and Russell. Pharmaceutical Microbiology, edition7th; Stephen P Denyer, Norman A Hodges and Sean P Gorman (editors). (2004) Pp 220-232; 285-303.Blackwell publishers, UK.

2. O. S.Alabi and E. A Sanusi. Efficacy of three disinfectant formulations against multidrug Resistant nosocomial agents. Afr. J. Cln. Exper. Microbiol. Sept 2012: 13(3): 178-82.

3. N.A. Rumi, M.M. Rahman, M.R. Akter, M. Fakhruzzaman and M.K. Hossain. Evaluation of the effectiveness of commercially available Disinfectants against salmonellae isolated from internal Organs of dead chicken. Bangl. J. Vet. Med. 2011: 9(1); 43 - 52.

4. Marin C, Hernandiz A and Lainez M. Biofilm development capacity of Salmonella strains isolated in poultry risk factors and their resistance against disinfectants. Poultry Science. 2009: 88(2):424-31. 
5. Heir E, Langsrud S, Sidhu MS, Steinbakk M: Can disinfectants contribute to antibiotic resistance? Neither Tidsskr nor Laegeforen. 2001:121 (27):3201

6. Ardakani FE., Zandi H, Mohammadi Z, Ayatollah J, Ayatollah F, Behniafar B. Comparing the Disinfecting Efficacies of Micro 10, Deconex, Alprocid and Microzid AF on the Microorganisms on radiographic equipments. JODDD, vol. 2, no. 2 spring 2008.

7. Sato $1 \mathrm{KK}$, Wachino J, Kondo T, Ito $\mathrm{H}$ and Arakawa $\mathrm{Y}$. Correlation between reduced susceptibility to disinfectants and Multidrug resistance among clinical isolates of Acinetobacter species J Antimicrobial Chemother, 2010; 24: 1-9.

8. Rutala A W, Barbee SL, , Aguiar CN, Sobsey D M, Weber DJ, Antimicrobial activity of home disinfectants and Natural Product Against potential human pathogens Infect Control Hosp Epidemiol 2000;21:33-8.

9. Eryýlmaz1M, Akm A and Akan Ö A, Investigation of the efficacy of some disinfectants against nosocomial gram negative bacteria. Int. Res. J. Pharma., 2012; Vol. 02, Issue 01, 1-5.

10. Charles $A^{*}$ and Alex Ramani V Phytochemical screening and antimicrobial resistance of Alseodaphne semecarpifolianees. J. Chem. Pharma. Res., 2011; 3(5):205-11.

11. Senthil K S, and Kamaraj M. Antimicrobial activity of Cucumis anguria L by agar well diffusion method. Botany Research International 2011; 4(2): 41-2.

12. Odeyemi O. A. , Ahmad A. and Usup G. In-vitro antimicrobial activity of Aeromonas spp isolated from estuary using different screening protocols. IJPSR, 2012; Vol. 3(2): 428-433.

13. Jain P, Aggarwal1 V and Singh A. Antimicrobial Activity of Extracts of Cyperus rotundus against Oral Pathogens and Its Synergistic Activity with Chloramphenicol and Fluconazole. Int. J. Trad. Nat. Med. 2012, 1(2): 83-91.

14. Bouzada M LM, Silva VL, Sa Moreira1FA, Silva GA and Diniz1CG. Antimicrobial resistance and disinfectants susceptibility of persistent bacteria in a tertiary care hospital. J Microbiol and Antimicrobials. 2010 November: Vol 2(8); 105-12.

15. Nogbulie NJ, Adieze EI and Nwankwo CN. Susceptibility pattern of some clinical bacterial isolates to selected antibiotics and disinfectants. Polish J of Microbiol, 2008: vol.57, No.3; 199-204.

16. Bohora Aarati, Hegde Vibha and Kokate Sharad. Comparison of the antibacterial efficiency of neem leaf extract and $2 \%$ sodium hypochlorite against E. faecalis, C. albicans and mixed culture - An in vitro study. Endodontology http://medind.nic.in/eaa/t10/i1/eaat10i1p8.pdf

TABLE 1: Efficacy of Savlon on MDR isolates in percentages

\begin{tabular}{|l|l|l|}
\hline Name of MDR isolates & ZOI of Disinfectants in $\mathrm{mm}$ & $\%$ \\
\hline
\end{tabular}


ORIGINAL ARTICLE

\begin{tabular}{|l|l|l|l|}
\hline & Savlon & Phenol & \\
\hline Escherichia coli & $34 \mathrm{~mm}$ & $42 \mathrm{~mm}$ & 80.95 \\
\hline Staphylococcus aureus & $33 \mathrm{~mm}$ & $40 \mathrm{~mm}$ & 82.5 \\
\hline Klebsiella pneumoniae & $29 \mathrm{~mm}$ & $41 \mathrm{~mm}$ & 70.73 \\
\hline Pseudomonas aeruginosa & $24 \mathrm{~mm}$ & $36 \mathrm{~mm}$ & 66.66 \\
\hline
\end{tabular}

TABLE 2: Efficacy of 70\% Ethanol on MDR isolates in percentages

\begin{tabular}{|l|l|l|l|}
\hline Name of MDR isolates & \multicolumn{2}{|l|}{ ZOI of Disinfectants in mm } & \% \\
\hline & $\mathbf{7 0 \%}$ Ethanol & Phenol & \\
\hline Escherichia coli & $34 \mathrm{~mm}$ & $42 \mathrm{~mm}$ & 80.95 \\
\hline Staphylococcus aureus & $32 \mathrm{~mm}$ & $40 \mathrm{~mm}$ & 80 \\
\hline Klebsiella pneumoniae & $36 \mathrm{~mm}$ & $41 \mathrm{~mm}$ & 87.80 \\
\hline Pseudomonas aeruginosa & $33 \mathrm{~mm}$ & $36 \mathrm{~mm}$ & 91.66 \\
\hline
\end{tabular}

Table: 3 Efficacy of Dettol on MDR isolates in percentages

\begin{tabular}{|l|l|l|l|}
\hline Name of MDR isolates & \multicolumn{2}{|l|}{ ZOI of Disinfectants in mm } & \% \\
\hline & Dettol & Phenol & \\
\hline Escherichia coli & $38 \mathrm{~mm}$ & $42 \mathrm{~mm}$ & 90.4 \\
\hline Staphylococcus aureus & $37 \mathrm{~mm}$ & $40 \mathrm{~mm}$ & 92.5 \\
\hline Klebsiella pneumoniae & $30 \mathrm{~mm}$ & $41 \mathrm{~mm}$ & 73.17 \\
\hline Pseudomonas aeruginosa & $36 \mathrm{~mm}$ & $36 \mathrm{~mm}$ & 100 \\
\hline
\end{tabular}

TABLE 4: Efficacy of Lysol on MDR isolates in percentages

\begin{tabular}{|c|c|c|c|}
\hline Name of MDR isolates & \multicolumn{2}{|c|}{ ZOI of Disinfectants in mm } & \% \\
\hline & Lysol & Phenol & \\
\hline Escherichia coli & $28 \mathrm{~mm}$ & $42 \mathrm{~mm}$ & 66.66 \\
\hline Staphylococcus aureus & $27 \mathrm{~mm}$ & $40 \mathrm{~mm}$ & 67.5 \\
\hline Klebsiella pneumoniae & $23 \mathrm{~mm}$ & $41 \mathrm{~mm}$ & 56.09 \\
\hline Pseudomonas aeruginosa & $20 \mathrm{~mm}$ & $36 \mathrm{~mm}$ & 55.55 \\
\hline
\end{tabular}

TABLE 5: Comparative Effectiveness of various disinfectants with phenol on multidrug resistant bacteria 


\section{ORIGINAL ARTICLE}

\begin{tabular}{|l|l|l|l|l|l|}
\hline MDR isolates & \multicolumn{3}{|l|}{ ZOI of Disinfectants in mm } \\
\hline & Savlon & Lysol & $\mathbf{7 0 \%}$ Ethanol & Dettol & Phenol \\
\hline Escherichia coli & $34 \mathrm{~mm}$ & $28 \mathrm{~mm}$ & $34 \mathrm{~mm}$ & $38 \mathrm{~mm}$ & $42 \mathrm{~mm}$ \\
\hline Staphylococcus aureus & $33 \mathrm{~mm}$ & $27 \mathrm{~mm}$ & $32 \mathrm{~mm}$ & $37 \mathrm{~mm}$ & $40 \mathrm{~mm}$ \\
\hline Klebsiella pneumoniae & $29 \mathrm{~mm}$ & $23 \mathrm{~mm}$ & $36 \mathrm{~mm}$ & $30 \mathrm{~mm}$ & $41 \mathrm{~mm}$ \\
\hline Ps.aeruginosa & $24 \mathrm{~mm}$ & $20 \mathrm{~mm}$ & $33 \mathrm{~mm}$ & $36 \mathrm{~mm}$ & $36 \mathrm{~mm}$ \\
\hline
\end{tabular}

FIG 1: Comparative Effectiveness of various disinfectants with phenol on multidrug resistant bacteria

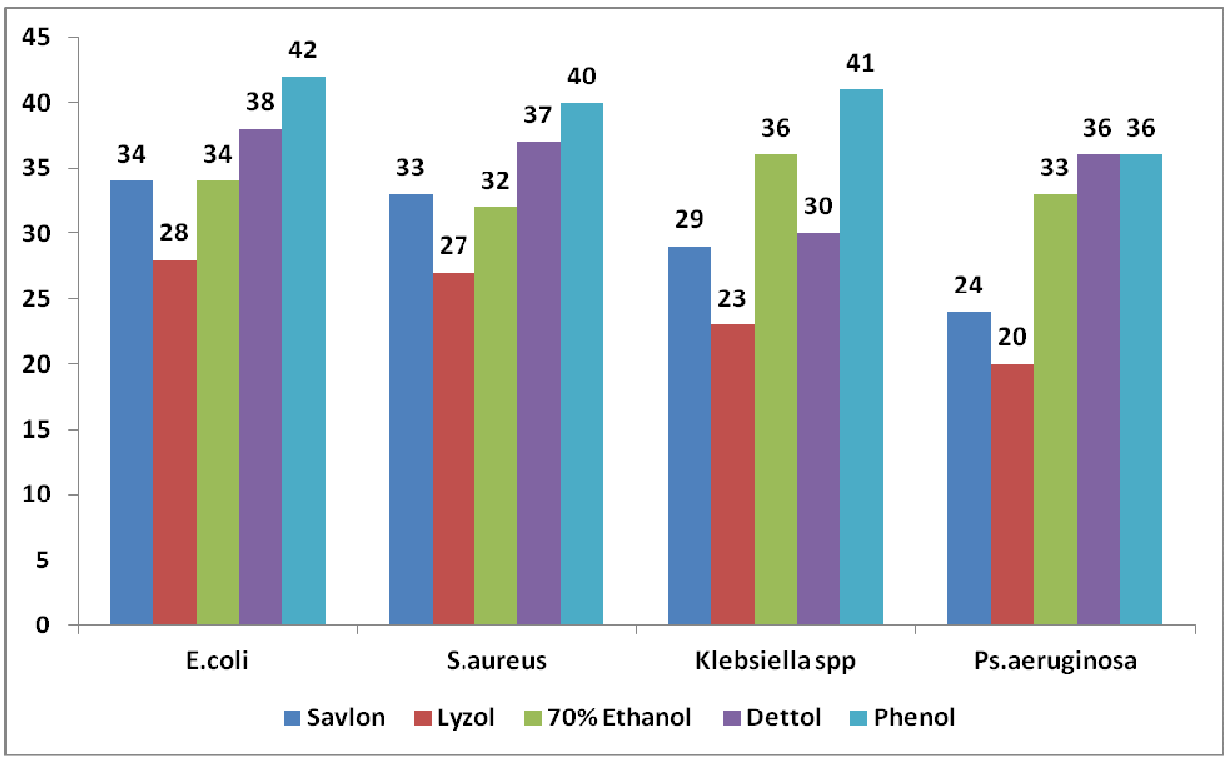

